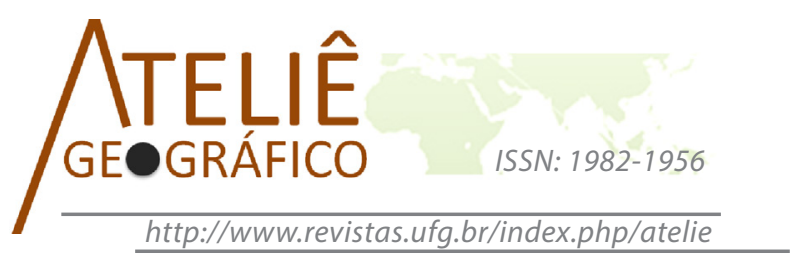

\title{
As ciências sociais e as mudanças climáticas
}

\author{
Social Sciences and Climate Change
}

Las ciencias sociales y los cambios climáticos

\author{
Allan Rogério Veltrone \\ Universidade Federal de São Carlos \\ allanveltrone@gmail.com
}

\begin{abstract}
Resumo
A proposta do artigo é mostrar o quão importante são as ciências sociais para a compreensão das mudanças climáticas. Trata-se de um tema inegavelmente hibrido, onde os aspectos sociais da questão são tão importantes quanto as analises dos cientistas do clima. Estas análises são realizadas com o objetivo de se elaborarem ações de mitigação, que devem contar, de alguma forma, com a participação do publico. Este, no entanto, tem mais facilidade para acessar os argumentos dos chamados céticos, que são, em sua maioria, divulgadores científicos, e não cientistas. Explorando estas controvérsias, mostraremos então a relevância de algumas teorias de autores consagrados: Beck, Latour, Giddens e Hanningan.

Palavras-chave: 1-Mudança Climática; 2-Sociologia da Ciência; 3-Sociologia Ambiental.
\end{abstract}

\begin{abstract}
The purpose of the article is to show how important social sciences are to understanding climate change. This is an undeniably hybrid theme, where the social aspects of the issue are as important as the analyses by the climate scientists. These analyses are performed in order to develop mitigation actions, which should depend, in some way, on the participation of the public. However, it is easier to access the arguments of so-called skeptics, who are mostly science communicators, and not scientists. Exploring these controversies, we then show the relevance of some theories by renowned authors: Beck, Latour, Giddens and Hanningan.

Keywords: 1-Change Climate; 2-Sociology of Science; 3-Environmental Sociology.
\end{abstract}

\section{Resumen}

El propósito de este artículo es mostrar la importancia de las ciencias sociales para la comprensión de los cambios climáticos. Se trata de un tema híbrido, donde los aspectos sociales son tan importantes como los análisis de los científicos del clima. 
Dichos análisis se realizan con el fin de desarrollar medidas de mitigación, las cuales deben contar con la participación del público. Sin embargo, es más fácil acceder a los argumentos de los llamados escépticos que, en su mayoría, son más comunicadores de la ciencia que científicos. Luego de estudiar estas controversias, mostraremos la relevancia de algunas teorías de autores de renombre: Beck, Latour, Giddens y Hanningan.

Palabras clave: 1-Cambio Climático; 2-Sociología de la Ciencia; 3-Sociología Ambiental.

\section{Introdução}

Seria muito improvável alguém hoje em dia nunca ter ouvido expressões como mudança climática, aquecimento global, etc.. Estas expressões estão presentes na ciência, na mídia, na politica, e em diversas outras instancias, e não são questões de fácil aceitação, havendo debates e discordâncias. Sendo assim, trata-se de um tema social, e não somente meteorológico ou geológico. Muitas abordagens sociais poderiam ser dadas ao tema: poderíamos olhar para as controvérsias entre os especialistas, para os afetados pelas mudanças climáticas, para a resiliência ou mudança do capitalismo e mesmo da geopolítica global, para as implicações de uma ciência de risco, para as significações sociais do tema, etc. Mas nossa proposta neste trabalho é mostrar a importância das ciências sociais para a compreensão das mudanças climáticas, nos focando em torno das controvérsias que existem em torno do tema.

Em primeiro lugar mostraremos o quanto de politica e cultura existem em torno da questão, não sendo suficientes somente as competências dos cientistas naturais. A existência dos chamados céticos ilustra também o quão controverso e incerto é o assunto, pois, não obstante o quase consenso da ciência em relação à realidade das mudanças climáticas, os argumentos dos céticos conseguem grande aceitação do publico norteamericano. Por outro lado, ainda haveria cientistas que criticam as previsões do IPCC (Intergovernmental Panel on Climate Change) por serem amenas demais. Em seguida, discutiremos algumas possíveis abordagens sociais do tema, nos valendo de autores consagrados, como Latour e seu conceito de rede bem como seu questionamento da ontologia moderna, a qual separaria artificialmente natureza e cultura; Hanningan e o analise da construção e legitimação de questões ambientais; Beck e a sociedade de risco, onde dependemos cada vez mais da ciência, mas já não confiamos tanto nessa instancia e Giddens e a modernidade reflexiva, onde os agentes continuam a serem modernos, mas refletem e fazem escolhas. Assim procedendo, acreditamos que ficará evidente a importância das ciências sociais para o debate sobre mudança climática.

No entanto, historicamente, as ciências sociais tardaram em entrar no debate ambiental, por conta de, principalmente, uma resistência ao chamado reducionismo biológico. A questão ambiental facilmente era confundia com uma questão dessa natureza (FERREIRA, 2001).

O nascimento do movimento ambientalista na década de 1960 surpreendeu os sociólogos, que não possuíam teorias para lidar com esse novo fenômeno (FERREIRA, 
2001). Além disso, o foco de analise das ciências sociais até então eram os processos de modernização e o ambientalismo, nesse contexto, poderia ser visto como atraso.

No entanto, nas duas ultimas décadas, as mudanças climáticas tem feito com que as ciências sociais produzam mais trabalhos na área ambiental, embora essa produção ainda seja pequena e dispersa em várias vertentes. Além disso, o próprio IPCC e outros institutos científicos como National Research Council (NRC), nos EUA, e o Millennium Ecosystem Assessment (MEA), tem avaliado a produção cientifica sobre as mudanças climáticas, e recomendado maior participação das ciências sociais no debate (MARTINS; FERREIRA, 2009).

Mas existem alguns problemas. A cooperação entre naturais e sociais, geralmente não vai além de parcerias pontuais em projetos, mesmo porque, as ciências naturais já lidam com a mudança climática há mais tempo, havendo um acumulo de teorias e métodos. No caso das sociais, existe também o problema de escala: as teorias sociais não mudam tão rapidamente quanto o clima e o conhecimento sobre ele (MARTINS; FERREIRA, 2009).

Mas uma vez que a questão vem recebendo mais atenção da mídia e se polarizando em diversas áreas cientificas e setores da politica, faz-se necessário uma maior dedicação das sociais ao tema. E é claro que alguns progressos tem ocorrido. Observase a proliferação de programas interdisciplinares, ressaltando-se a contribuição de áreas como geografia, demografia, antropologia, ciência politica, relações internacionais, economia e sociologia (MARTINS; FERREIRA, 2009).

Embora os cientistas sociais estejam tendo dificuldade em adequar suas agendas de pesquisa as mudanças climáticas, sua contribuição seria de grande valor para o debate.

No que tange a mudança climática, risco (BECK, 2011) e reflexividade (GIDDENS, 1991) são fatores inerentes. Há que se compreender melhor as mudanças na ciência e na legitimidade dela. E se por um lado as ciências sociais tem dificuldades com a escala da mudança climática, as naturais não possuem métodos e teorias para lidar com a complexidade de fatores envolvidos nas questões ambientais (MARTINS; FERREIRA, 2009), as quais, sempre, serão também questões sociais.

Assim, quando os cientistas naturais dizem coisas como: “as populações de Panthera onca da mata atlântica chegaram a níveis tão baixos, que se não forem tomadas imediatamente medidas drásticas, a espécie desaparecerá deste bioma" (AGENCIA FAPESP, 2014), espera-se que as tais medidas drásticas sejam tomadas. Mas não é assim que acontece. Há que se olhar para a rede (LATOUR, 2013) na qual o objeto está inserido. Há que se olhar para os pareceres da ciência, para os criadores de gado que matam as onças, para quem e porque desmata o habitat do felino, para a dinâmica populacional do animal, para os governos responsáveis por promover a preservação da espécie, etc. E aqui se trata de uma questão mais tipicamente latino-americana: embora a América Latina emita relativamente pouca quantidade de gases do efeito estufa (em comparação com China, EUA e Europa), o continente possui muitos estados-nação que baseiam sua economia em commodities agrícolas, os quais fazem a sua produção se expandindo por áreas de ecossistemas até então preservados. O continente necessita de governança e 
justiça ambiental (MARTINS; FERREIRA, 2009), até porque, é a região do mundo com maior desigualdade social (UN, 2007).

No entanto, nosso foco de analise será a produção de países centrais, especialmente os Estados Unidos, em menor medida a Europa.

No Brasil e na América Latina, mudança climática ainda não é uma área de pesquisa institucionalizada, sendo os trabalhos existentes esparsos e fragmentados, embora se assista a um crescimento (MARTINS; FERREIRA, 2009).

A pesquisa social sobre o tema acompanha o debate internacional, mas leva mais em conta questões de interesses nacionais e regionais, como desigualdade social, pobreza, presença de populações tradicionais e alta biodiversidade, temas estes, que, em grande medida, são uma demanda de algumas áreas das ciências naturais. O que pode ser encarado com moderado otimismo, pois se, por um lado, a produção latino-americana é pequena, já se pode visualizar um caminho para a interdisciplinaridade (MARTINS; FERREIRA, 2009).

\section{Histórico da Questão Climática e o IPCC}

Nos últimos 150 anos, a temperatura da Terra vem aumentando, e o IPCC, principal órgão responsável por definir ações e conceitos sobre tema, trabalha com uma prerrogativa de manter o aquecimento futuro em $2^{\circ}$ Celsius (GIDDENS, 2009).

Isso porque a temperatura poderia subir até $4^{\circ}$ Celsius. Se isso acontecer, um terço das espécies do planeta pode desaparecer. Além disso, com o derretimento dos polos, o nível dos oceanos subiria de 18 a $58 \mathrm{~cm}$ até 2100, o que deixaria diversas ilhas e cidades costeiras submersas deixando centenas de milhares de desabrigados, e um bilhão sem agua potável, sendo que as perdas em vidas humanas poderiam ser maiores do que a das duas grandes guerras juntas. (BBC BRASIL, 2007; HUNG; TSAI, 2012). $\mathrm{E}$, segundo o IPCC, pelo menos até o presente momento, não existe nenhum indicativo de que as sociedades possuem os meios necessários para se adaptarem a essas mudanças (ABRAMOVAY, 2014).

Não se fala mais em impedir o aquecimento global. O IPCC e a maior parte da comunidade cientifica considera a mudança climática uma realidade. É possível até que isso seja a maior ameaça que já houve sobre a humanidade (SCHOIJET, 2008) e tem se tornado assunto cada vez mais corriqueiro. Seja na mídia, seja enquanto norte de ações coletivas, seja na ciência, havendo diversas discordâncias quanto sua origem, quanto a real dimensão da mudança e quanto às medidas para mitiga-la.

As ciências do clima ganham forma a partir da década de 1950, especialmente nos EUA, através da geofísica. Esta área recebia grandes aportes financeiros do governo deste país, devido à importância militar da disciplina (satélites e outros instrumentos de monitoramento remoto) (DOEL, 2003). 
Em 1971, James Lovelock, criador da Teoria de Gaia e então cientista da NASA ${ }^{1}$, desenvolve um equipamento capaz de medir as concentrações de $\mathrm{CFC}^{2}$ da atmosfera. Em 1972, mesmo ano do fórum de Estocolmo, durante um encontro de climatólogos, discutiu-se a respeito de uma nova era glacial. A conclusão a que se chegou, foi a de que esta era não chegaria devido a grande quantidade de $\mathrm{CO}_{2}$ presente na atmosfera (SCHOIJET, 1988).

A mídia afirma a existência do aquecimento global pela primeira vez, em 1981, através de uma matéria de Walter Sullivan, publicado no jornal The New York Times e baseado em um artigo do cientista James Hansen. No entanto, no dia seguinte o jornal publica uma nota afirmando serem as evidencias insuficientes (SCHOIJET, 2008).

Em 1988 é criado o IPCC, que surge justamente da percepção de que a ação humana altera o clima (OROMBELLI, 2010). A Grande visibilidade que o tema tem tido, pode ser em partes creditada a essa instituição.

Trata-se de um órgão das Nações Unidas, que conta com delegações de 130 países e que tem como objetivo realizar avaliações periódicas do estado do clima na Terra. O IPCC não faz pesquisa, apenas compila dados de pesquisas existentes.

Os relatórios são produzidos em quatro etapas. A primeira, mostra evidencias cientificas de que a mudança climática esta ocorrendo. Na segunda, são apresentadas as consequências destas mudanças, e a terceira propõe soluções. A quarta seria uma síntese das anteriores. Esta ultima etapa deve antes ser discutida entre os chefes de Estado. (BBC BRASIL, 2007).

O primeiro relatório é de 1990, e concluiu que seria necessária a criação da Convenção Quadro das Nações Unidas sobre Mudança Climática (UNFCCC). Em 1992 tem-se a Eco 1992, grande marco para o ambientalismo da década de 1990, bem como do ambientalismo como um todo. (LEIS, 2004). Ali foi elaborada a Agenda 21, a Convenção sobre Biodiversidade Biológica e a Convenção Quadro sobre mudanças climáticas (IPAM, 2015).

O segundo é de 1995. Neste relatório, conclui-se que até 2080, 50\% da Amazônia poderá se tornar savana, e $75 \%$ das fontes de agua potável do semiárido brasileiro podem desaparecer até 2050. No entanto, o próprio IPCC admite que não existe muita pesquisa sobre clima em países em desenvolvimento, como o Brasil, e que, portanto, os dados seriam menos confiáveis (BBC BRASIL, 2007).

Consequência direta do segundo relatório, em 1997 o Protocolo de Kyoto é firmado, tendo sido elaborado durante a III Conferência das Partes da UNFCCC (COP-3). Trata-se de um acordo internacional que visa à redução das emissões dos principais gases do efeito estufa (IPAM, 2015).

Para entrar em vigor, o protocolo deveria ser ratificado por pelo menos 55 das nações pertencentes à UNFCC. As nações poderiam estabilizar as emissões até 2030, mantendo um patamar razoável. Isso custaria somente $3 \%$ do PIB mundial (IPAM,

1. National Aeronautics and Space Administration

2. Composto Clorofluorcarbono 
2015). O grande problema aqui foram os Estados Unidos, então responsáveis por 36\% das emissões. Os EUA se negaram a assinar, e o tratado só começou a valer em 2005, com a entrada da Rússia e de quase todos os países desenvolvidos (IPAM, 2015).

Estes acordos, no entanto, apresentam a clássica tensão norte x sul, onde os países desenvolvidos cobram dos países em desenvolvimento que reduzam suas emissões de carbono, enquanto os países em desenvolvimento afirmam que se fizerem isso, não poderão atingir o mesmo patamar dos países desenvolvidos, os quais, afinal, teriam sido os grandes responsáveis pela maior parte das emissões já lançadas.

O protocolo de Kyoto obriga os países do chamado Anexo I, que são cerca de 40 estados nação desenvolvidos e pertencentes ao antigo bloco soviético a reduzir suas emissões de gases do efeito estufa a uma media de 5,2\% abaixo das emissões de 1990. As metas variam para cada país, e isto deveria se dar até 2012 (IPAM, 2015).

Os países em desenvolvimento, excluídos do Anexo I, tem adesão voluntaria ao protocolo, mas seu papel é crucial nestas negociações. Índia e China são responsáveis por $25 \%$ das emissões de gases de efeito estufa, mas também não se comprometeram em reduzir. As nações em via de desenvolvimento necessitam de multinacionais, que produzem a custa de grandes emissões de gases de efeito estufa. Quanto ao Brasil, a atividade industrial não é das mais poluentes, mas as queimadas e o desmatamento são alarmantes (SCHOIJET, 2008). No entanto o pais propôs a criação do Fundo de Desenvolvimento Limpo, que aplicaria multas aos países desenvolvidos que não atingissem suas metas, sendo que o dinheiro deveria ser utilizado para financiar projetos de desenvolvimento sustentável nos países em desenvolvimento. A proposta foi rejeitada, mas em parceria com os Estados Unidos, o Brasil a reformulou, e foi assim criado o Mecanismo de Desenvolvimento Limpo, que prevê a possibilidade de os países que não cumprirem suas metas comprarem créditos de outros países que cumprem e possuem saldo (VIOLA, 2002). O próprio Banco Mundial recomenda o comercio de carbono, onde um país que não atinge as metas de redução poderia pagar para que outro país preserve suas florestas, pois as arvores retiram carbono da atmosfera (NOZAWA, 2010).

O terceiro relatório é de 2001. Este relatório considerou que haveria uma probabilidade de $66 \%$ de que a mudança climática teria causas antrópicas (BBC BRASIL, 2007).

O quarto é de 2007, e foi apresentado na Conferência do Clima de Bali. Neste, considerou-se que haveria $90 \%$ de chance de que o aquecimento fosse causado por ação antrópica (BBC BRASIL, 2007). O objetivo da Conferencia era avaliar os resultados obtidos a partir de Kyoto. O resultado, no entanto, não foi como o esperado, havendo uma posterior redução de apenas $0,8 \%$. Os EUA não se comprometeram com as reduções, embora o custo não ultrapassasse os $0,06 \%$ do PIB desta nação (ANTONUCCI, 2010). Paradoxalmente, o tratado de Montreal, que visava reduzir as emissões do gás $\mathrm{CFC}$, principal responsável pelo buraco na camada de ozônio, logrou êxito, praticamente banindo o composto do mercado (SCHOIJET, 2008). Não é nosso objetivo aqui, mas seria interessante comparar o porquê desse tratado ter tido êxito, enquanto o de Kyoto ainda patina, oscilando entre êxitos pontuais e metas quase sempre não cumpridas. 
A novidade aqui reside no Mapa do Caminho de Bali, um documento que visa simplificar a adesão ao tratado, e que cria um fundo de recursos para que os países em desenvolvimento se adaptem a produzir com baixas emissões de gases do efeito estufa (PROTOCOLO DE KYOTO INFO, 2015).

$\mathrm{O}$ interesse e o envolvimento das nações do planeta diverge. Embora seja um tema transnacional por natureza, faz necessário um ator que impulsione (e pressione) o processo de negociação. Não obstante a importância de emergentes como Brasil, China e Índia, o regime de governança das mudanças climáticas, é reflexo do posicionamento de países desenvolvidos e dotados de solido aparato institucional, como EUA e a União Europeia (VIOLA, 2002).

Os países desenvolvidos e a maior parte dos emergentes são geridos por regimes democráticos. Ocorre, no entanto, que as nações democráticas são constituídas por grupos de pressão e interesse, e a influencia que estes grupos têm sobre a nação, resultando na sua posição quanto à politicas internacionais, varia ao longo do tempo, e justamente por isso, os países mudam seu envolvimento com o assunto. Quando falamos, por exemplo, da posição brasileira ou da posição estado-unidense sobre a mudança, estamos falando do resultado de um arranjo interno de diferentes setores destes países. Arranjos estes que mudam (VIOLA, 2002).

Segundo Viola (2002), as coalizações de interesses se dividem em: países desenvolvidos com alta taxa de emissão de gases de efeito estufa, países desenvolvidos com media intensidade, países desenvolvidos com media intensidade, mas que tem dificuldades em reduzir, países pertencentes a ex-União Soviética que sofreram uma drástica redução de emissões, países exportadores de petróleo, países pobres, pequenos estados-ilha, países emergentes com baixa taxa de emissão e países emergentes com media emissão.

Quanto aos emergentes com media taxa de emissão, grupo no qual o Brasil se insere, em geral suas economias consomem grandes quantidades de carvão ou petróleo (Índia, México, África do Sul e China). São moderadamente favoráveis ao regime de mitigação, devido aos benefícios que teriam com a implementação do Mecanismo de Desenvolvimento Limpo, mas alguns setores são contra. Seus regimes políticos baseiamse geralmente em coalizações entre neoliberais e neosocialdemocratas (neoliberais e nacionalistas, no caso da China), com influencia de setores nacionalistas.

Dentro deste grupo, a China é um caso significativo. Um dos países mais importantes para a economia mundial, também é um dos que mais emitem gases do efeito estufa. A China, e consequentemente a economia global, sofreria muitos danos com as mudanças climáticas: derretimento de geleiras, perdas na agricultura, aumento das secas em mais de 10\%, tempestades, inundações e aumento do nível. 67 milhões de pessoas seriam atingidas. Tudo isso acarretaria em aumento das migrações, que já ocorrem. Além da migração externa, haveria grandes deslocamentos internos, resultando em inchamento da cidade e em possíveis conflitos étnicos. E afinal, estamos falando de um pais com mais de um bilhão de habitantes (HUANG, TSAI, 2012). 
No entanto, a China estaria investindo em algumas ações pro-mitigação, como matriz energética de baixo carbono, plantio de arvores e disciplinamento da agricultura, levando a produção para próximo de grandes centros urbanos além de controlar as migrações internas. É claro que estas duas ultimas ações, são mais facilmente executáveis sendo a China um regime autoritário (HUANG, TSAI, 2012).

Brasil, Tailândia, Malásia e Filipinas fazem parte desse grupo, e não são grandes consumidores de petróleo tampouco carvão. No entanto, são grandes desmatadores, e a maior parte de suas emissões parte dessa fonte (VIOLA, 2002).

No entanto, apesar de contar com uma minoria verde, o Brasil, pais que, junto a outros, exerce liderança no bloco dos países em desenvolvimento, tem se mostrado relutante em reduzir suas emissões. Não obstante, a grande visibilidade mundial do desmatamento ocorrido na Amazônia, obriga o país a prestar contas ao mundo (GIDDENS, 2009).

A posição brasileira, no entanto vem mudando desde o fórum de Estocolmo. Em 1972, o Brasil, junto da China, apresentava-se refratário a limitar o desenvolvimento econômico por causa do risco ambiental, defendendo modelos econômicos baseados em grande utilização de recursos naturais e em mão de obra barata (VIOLA, 2002).

Na década de 1980, com a crise econômica nacional e as mudanças tecnológicas nos modos de produção, o Brasil busca um alinhamento político-econômico mais forte com o resto do mundo. Embora ainda na década de 1990 o país possua importantes setores nacionalistas, já não era mais possível ignorar a opinião estrangeira (VIOLA, 2002).

Embora os governos de Fernando Collor de Mello e de Fernando Henrique Cardoso tenham produzido grandes avanços na área ambiental, o sucesso do Plano Real e as politicas neoliberais nacionalistas incentivaram uma ocupação mais intensa da Amazônia, e o consequente desmatamento, agravado com a incapacidade e até conivência dos Estados Amazônicos e instituições fiscalizadoras (VIOLA, 2002).

Aqui as politicas em torno das mudanças climáticas são em grande medida reflexos das politicas internacionais, como ocorre com a questão ambiental em geral. Tem-se uma considerável participação de ONGs (Organizações não-governamentais) no processo, com destaque para o World Wildlife Foundation (WWF), ong internacional com escritórios na Brasil, e que trabalha em parceria com instituições e outras ONGs do pais. Também tem tido papel articulador o Fórum Nacional de Mudanças Climáticas, bem como os planos plurianuais. Os ministérios de Meio Ambiente, Ciência e Tecnologia e Relações Internacionais tem sido os mais pró-mitigação (CERESAN, 2011). Mas em suma, o papel do Brasil para o agravamento ou mitigação das mudanças climáticas, se dá principalmente em torno da Amazônia. A floresta poderia ser um trunfo por conta dos sumidouros de carbono, mas se torna um ônus por causa do desmatamento (VIOLA, 2002).

Giddens defende que as clássicas tensões norte $\mathrm{x}$ sul presentes desde o fórum de Estocolmo, deferiam ser resolvidas com os países industrializados reduzindo, e até parando seus processos de crescimento econômico (intrinsecamente poluidores), 
enquanto os subdesenvolvidos deveriam ser encorajados a atingir o mesmo patamar dos ricos, para depois pararem (GIDDENS, 2009).

Embora os tratados em torno da questão climática não discordem do autor, este, no entanto, seria o melhor dos mundos, e o próprio Giddens não crê que isto esteja a ocorrer. As mudanças climáticas já vêm alterando recursos naturais, como o ressecamento do lago Chade no Sudão, o que resultou em migração em massa, que por sua vez resultou em guerra civil, com apoio militar da China (o Sudão possui reservas de petróleo) (GIDDENS, 2009).

Assim, mesmo que as nações democráticas entrem em acordos de cooperação, nações geopoliticamente estratégicas são governadas por regimes autoritários, ou democracias instáveis, como China, Rússia e diversas nações do oriente médio.

\section{Controvérsias: negação das mudanças climáticas}

Redundante seria dizer que o tema das mudanças climáticas é controverso e incerto. Embora a questão tenha ganhado legitimidade a partir das ciências naturais, é fato que o tema transcende as disciplinas ambientais, meteorológicas e geológicas (HANNINGAN, 1995).

As discussões em torno das mudanças climáticas se pautam pelos conceitos de vulnerabilidade, incerteza e mitigação, sendo que os cenários construídos pelo IPCC se baseiam em previsões para o futuro, previsões estas que sempre se alteram (BBC BRASIL, 2007).

Surgem então diversos desdobramentos na politica e na ciência, lembrando que o próprio IPCC deixa clara a necessidade de mais trabalhos na área de ciências sociais (MARTINS; FERREIRA 2009).

Mas não obstante a legitimidade do órgão e dos citados fóruns, existem céticos do aquecimento global. Os geólogos Fredd Singer, Dennis Avery e Patrick Michaels afirmam que o IPCC é composto de só um terço de cientistas, os demais seriam representantes de interesse na indústria da mitigação de carbono. Afirmam os autores que o atual aquecimento da Terra é moderado e não é produzido pelo homem. Já o cientista politico Bjorn Lomborg afirma que o aquecimento global existe e de fato é causado pelo homem. As consequências, no entanto, não seriam tão graves, havendo problemas mais urgentes, como epidemia de AIDS, miséria e armas nucleares (GIDDENS, 2009).

Os jornalistas Christopher Booker e Richard North não se aprofundam nas origens e consequências do aquecimento, mas afirmam estarmos vivendo uma era de pavores. Céticos como estes jornalistas, afirmam que a percepção de risco pelo publico é falsa. As estatísticas mostram que é muito mais provável um individuo morrer em um acidente de carro do que em um acidente de avião, por exemplo. No entanto, mais pessoas tem medo de avião do que de carro (GIDDENS, 2009).

Embora a ciência se beneficie, e em grande medida dependa da controvérsia, há que se ter cuidado. Em primeiro lugar, os céticos são em grande parte divulgadores 
científicos, e não cientistas. E estes escrevem para seus pares, ao contrario daqueles, que escrevem para o grande publico.

Já em meados da década de 1960, os cientistas e em menor medida o governo dos Estados Unidos, sabiam da possibilidade de as mudanças climáticas ocorrerem e de que este evento teria grandes consequências. Foi entregue ao congresso dos EUA um relatório com cinco capítulos, contando com a participação de economistas e cientistas do clima, entre eles James Hansen e Suki Manabe, -dois dos mais respeitados nomes da area- onde a magnitude das mudanças climáticas parecia assumir a dimensão que hoje tem. O congresso norte americano, no entanto, não deu nenhuma importância a questão, e nenhuma politica foi implantada. No entanto, depois de 1988, data do surgimento do IPCC, e também a partir da crescente visibilidade do trabalho de já citado Hansen, a questão não poderia mais ser ignorada (ORESKES; CONWAY, 2010).

Em 1989, um ano depois da criação do IPCC, foi criada a Global Climate Coalition, uma coalizão de indústrias petroleiras dos EUA, como Mobil e Olin. A coalização recebeu apoio do congresso, bem como de importantes mídias deste país, como Forbes e Wall Street Journal (SCHOIJET, 2008). Antes disso, no entanto, Fredrick Seitz, Robert Jastrow e Willian Nieremberg criam o Instituo George Marshal, com foco em assuntos científicos e politicas publicas. O instituto se tornou conhecido como um nicho de pensamento conservador e negacionista em relação a riscos ambientais. A maior parte das conclusões dos céticos não consegue ser publicada em revistas cientificas, mas muitos livros são editados por este instituto (ORESKES; CONWAY, 2009).

Muitos nomes importantes fizeram parte desta campanha, como Robert Willians, assessor da indústria petroleira, que em 1991 apregoava na mídia a necessidade de desacreditar os movimentos ambientalistas, sob pena de, se os americanos não o fizessem o país vir a ter sérios problemas econômicos (SCHOIJET, 2008).

Frederick Seitz publica um artigo em 1998 onde afirma ser o aquecimento global "um presente da Revolução Industrial." Seitz é um renomado físico militar da década de 1940, que passou a ocupar altos cargos no governo norte-americano, como por exemplo, assessor presidencial na Comissão de Energia Atômica. Antes disso, Seitz, juntamente de Singer, foram responsáveis pela controvérsias em torno dos males do fumo. Não obstante o acumulo de evidencias cientificas atestando o mal, a campanha se focava nos poucos pontos nebulosos, dando a impressão de que de fato existe uma controvérsia. $\mathrm{O}$ argumento da indústria tabagista, no entanto, foi derrubado, a partir do vazamento de documentos das próprias companhias de cigarro, que atestavam os males do tabaco, isso em 1964. Quanto a Singer, ele já era um cético conhecido desde a década de 1980, se mostrando uma liderança contraria ao tratado de Montreal, que visava a redução do uso de $\mathrm{CFC}^{3}$ s nos aerossóis (LEITE, 2014).

$\mathrm{O}$ artigo foi publicado na Energy and Environment, uma revista cientifica norte-americana conhecida por abrigar publicações de céticos. Em entrevista, quando questionada quanto a publicação de um artigo com fracas evidencias (segunda as demais

3. Clorofluorocarboneto 
revistas onde Seitz tentou publicar) a editora Sonja Boehmer Christensen, afirmou que "a revista tem sua própria agenda politica" (SCHOIJET, 2008).

A função da coalização foi a de deslegitimar o IPCC, e alguns cientistas em particular, bem como negar ou minimizar a existência do aquecimento global, criando uma falsa controvérsia. Não é que a controvérsia não exista, mas certamente que empresas do setor petroleiro não seriam as "instituições científicas” mais confiáveis para tratar do tema. No entanto, os céticos conseguiram relativo êxito na formação da opinião publica. Além disso, em 1989, lançam um livro intitulado: “Global Warming: What's Science has to Say", onde defendem que o aquecimento seria causado por flutuações das radiações solares, e que esse aquecimento não passaria de 0,5 graus Celsius (ORESKES; CONWAY, 2010).

A conclusão do livro é rejeitada pelo IPCC, mesmo porque, mais ou menos no mesmo período, outro climatologista, chamado Benjamin Santer, desenvolve modelos que diferenciam a radiação solar da radiação que vem da atmosfera. Se não tiver ocorrido grande atividade vulcânica no período analisado, então a radiação só pode ter origem antrópica (ORESKES, CONWAY, 2010).

Em 2004, a revista Discovery publica uma matéria onde afirma não haver discordância em relação a este assunto: o clima do planeta está esquentando, e por causas antrópicas. Já a revista Times publica uma pesquisa de opinião que diz que somente $56 \%$ dos norte-americanos acreditam na existência do aquecimento global. E a maior parte dos entrevistados acredita existirem mais controvérsias do que de fato existem (ORESKES; CONWAY, 2010).

Segundo dados compilados de Nisbet e Meyers (2007), em 1986, 23\% dos norte-americanos já ouviram falar de aquecimento global. Em 2007 eram mais de 90\%. No entanto, somente $23 \%$ estariam convencidos da sua realidade.

Mas ainda assim, em 2007, os norte-americanos apontaram o aquecimento global como o maior dos problemas ambientais. Em anos anteriores, era a qualidade da água (NISBET E MEYERS, 2007).

Além disso, a complexidade do tema, e a serie de fatores correlacionados, confunde o publico (e mesmo os cientistas não se encontram de acordo em relação aos efeitos em cadeia provocados pelas mudanças climáticas). Eventos geograficamente distantes, como o derretimento do gelo no ártico, o qual por sua vez modifica as correntes marítimas, causando furacões, são de difícil compreensão. E fica ainda pior, pois, embora em media a temperatura do planeta esteja se aquecendo, as mudanças climáticas podem causar um inverno rigorosamente frio, como vem ocorrendo no hemisfério norte (RIVA, 2010).

Quanto ao alcance do risco, o publico tende a pensar em si mesmo e nas suas famílias ou na humanidade como um todo. Raramente correlacionam mudança climática com sua localidade, e também não consideram ser esta uma questão fundamental, pois haveria questões mais importantes, como saúde, economia e segurança. A ciência chega ao publico mediada pela mídia, que por sua vez, é pouco cientifica. De um lado, os catastrofistas, que utilizam expressões como "ponto de não retorno", e de outro, os 
negacionistas, que se valem dos argumentos dos catastrofistas para deslegitimarem as ciências do clima, e mesmo questionar a existência do aquecimento global (RIVA et. al, 2010).

Mike Lockwood, físico que afirma a existência do aquecimento global e nega qualquer causa não-antrópica, diz que o publico ouve os céticos porque estes dizem o que as pessoas querem ouvir (SCHOIJET, 2008). E de fato, é mais confortável pensar que não existe aquecimento ou que existe, mas que nada podemos fazer. Além disso, como já dito, os cientistas escrevem para seus pares, enquanto os divulgadores escrevem para o grande publico. Sendo assim, mesmo que seus argumentos não tenham muita fundamentação, atingem um publico maior e são mais facilmente compreendidos (ORESKES; CONWAY, 2010).

A partir do buscador "climate change", pode-se constatar que a maior parte dos artigos encontrados na web of Science, afirma a existência do aquecimento global e que o mesmo tem origem antrópica. É claro, não necessariamente os cientistas afirmam com essas palavras, mas é que já se sabe que o clima do planeta muda, e que está mudando mais rápido do que os modelos previam, e que nenhum outro fato explica melhor essa mudança do que a ação antrópica (ORESKES, 2007; ORESKES; CONWAY, 2010).

Embora o próprio IPCC afirme que exista $90 \%$ de chance da mudança ser causada pelo homem, e não exista nenhuma maneira de comprovar com $100 \%$ de certeza, não existe nenhum motivo para acreditar que a mudança climática não esteja ocorrendo. Os céticos, além de não serem cientistas (ou são, mas não tiram suas conclusões a partir de pesquisas cientificas), se limitam a questionar a ciência, os métodos de laboratório, etc.. E como se não bastasse, o clima da Terra vem sendo medido desde o século XIX, e desde então, a temperatura só vem aumentando. Seria absurdo inferir que o próximo ano será mais quente do que o anterior? (ORESKES; CONWAY, 2010).

Mas nem só de métodos indutivos vive a ciência do clima. A maior parte das teorias sobre aquecimento vem se confirmando. Desde antes do século XX, sabe-se que o $\mathrm{CO}_{2}$ na atmosfera causa efeito estufa. Sabe-se também que a quantidade de $\mathrm{CO}_{2}$ vem aumentando. E também as medições mostram que a temperatura vem aumentando. Seria então imprudente deduzir que o $\mathrm{CO}_{2}$ causa efeito estufa? E mais, uma vez que é sabido que a atividade industrial, -que até então só vem aumentando- emite $\mathrm{CO}_{2}$, que razão teríamos para duvidar que o aquecimento -na velocidade atual- tem causas antrópicas? (ORESKES, 2007)

De qualquer maneira, os céticos são minoria, e não são ouvidos pelo IPCC. O que eles têm em comum, é não acreditarem totalmente nas previsões deste órgão (GIDDENS, 2009).

Mas se já existe um consenso na ciência de que o aquecimento global existe e tem causas antrópicas, como então tão poucos indivíduos, como Seitz e Singer, conseguem ter tanto influencia? Isso se deve ao acesso privilegiado que ambos possuem no poder. Não conseguem publicar suas analises negacionistas em revistas cientificas, mas em periódicos jornalísticos sim. A maior parte dos norte-americanos e boa parte da população do planeta conhece o IPCC, mas o leigo não acessa seus relatórios. Estes 
fatores afetam a opinião publica vide o baixo envolvimento da politica norte-americana com a questão (ORESKES, CONWAY, 2010).

\section{Criticas ao IPCC: errar para o menos dramático}

Existem também os céticos que acusam o IPCC de ser ameno. Brysse (et. al, 2013) dizem que muitas das previsões presentes nos relatórios se mostraram amenas diante dos fatos, como o derretimento do permafrost e do gelo dos polos e a ocorrência de furacões.

Ainda citando Brysse (et. al 2013), os cientistas do IPCC operariam a partir do que os autores denominam de ESLD- erring on the side of least drama. ${ }^{4}$ Isso equivale a dizer que, na duvida, as previsões são sempre feitas considerando-se a possibilidade mais otimista. Os autores chegam a ousada conclusão de que a influencia da mídia e da politica norte-americana influenciaria até o posicionamento dos cientistas. Não nos apressemos em endossar ou refutar essa conclusão, mas temos razões para considera-la uma premissa valida, conforme os argumentos que apresentamos até agora.

Os cientistas que falam sobre mudança climática, mas que são amenos conseguem mais financiamento e publicações. Para Schoijet (2008), este é um procedimento socialmente irresponsável. Os cientistas deveriam parar de esperar por provas incontundíveis antes de recomendar ações de mitigação, pois afinal, quando mais se demora a agir, maiores e mais imprevisíveis se tornaram os efeitos, além dos efeitos em cadeia. Por exemplo, a falta de chuva diminui o crescimento das árvores, que por sua vez, passam a reter menos carbono (PESQUISA FAPESP, 2014).

Richard Pearce diz que a mudança será abrupta, e não gradual. E o cientista espacial James Hansen diz que o aquecimento global implica em perigos incertos e não mensuráveis. O derretimento do permafrost na Sibéria (o que de fato vem ocorrendo) libera imensas quantidades de gás carbônico e metano. E pouca pesquisa se tem feito a esse respeito (GIDDENS, 2009).

\section{Ciências Sociais e as Mudanças Climáticas}

Os cientistas podem questionar o tamanho da mudança climática, podem questionar os métodos do IPCC, etc.. Mas as evidencias apontam para uma direção: o clima está esquentando (ORESKES, 2007).

Isso basta? Não, porque os cientistas naturais se encarregam de qualificar e quantificar a mudança climática, mas cabe à sociedade implantar os mecanismos de redução de mitigação. E muitos setores, ou não concordam com a relevância da questão, ou são contrários.

A questão climática é composta pelo IPCC, pelas pesquisas que compila, pelos fóruns globais, pela mídia, e até pelo clima propriamente dito! Tudo isso poderia ser

4. Errar pelo lado menos dramático (tradução livre) 
compreendido como a ontologia do carbono, a qual por sua vez é composta por diversos fatores (FERNANDEZ et. al., 2014).

Estes diversos outros fatores podem ser compreendidos como uma rede, que engloba agentes humanos e não humanos, os quais Latour denomina actantes. Participam da rede as entidades, instituições, laboratórios, cultura, valores, objetos, indivíduos, etc. Ou seja, são elementos constituintes das redes, toda e qualquer instancia capaz de provocar mudanças (LATOUR, 2012a).

Não se trata, de maneira nenhuma, de se enxergar os fatores sociais por trás dos objetos, mas tampouco, de tomar os objetos como dados. Sendo uma rede, com diversos fatores interligados, a inovação interage com o pré-estabelecido, em um processo que não se resume em relações de poder, mas que também não é isento delas. É o que Latour denomina de Actor-Network-Theory (ANT) (LATOUR, 2012).

A questão climática é complexa, e questões complexas demandam interdisciplinaridade, sendo que já podemos visualizar a formação de uma nova área, a ciência do clima (CERESAN, 2011).

Como já dito, as ciências sociais entram tardiamente no debate ambiental, e isso tem reflexos para a ciência do clima. Em levantamento realizado em torno de grupos de pesquisa com registro no $\mathrm{CNPq}$, constatou-se que a grande maioria era relacionados as engenharias e ciências da terra. Havia alguns poucos grupos de ciências sociais, mas nenhum interdisciplinar (CERESAN, 2011).

Muito se fala sobre mitigação, que seria um aspecto mais característico das ciências naturais. Mas pouco se fala sobre adaptação, que seria um aspecto que caberia às ciências sociais trabalharem (GIDDENS, 2009).

Dessa forma, questões sociais inerentes são ignoradas, como a desigualdade da exposição ao risco. A interdisciplinaridade seria o passo fundamental para se fazer a transição entre ciência e politica (CERESAN, 2011).

Hanningan (1995), um dos pioneiros da sociologia ambiental, afirma que a ciências sociais, historicamente, tem mostrado relutância em abarcar o ambiente nas suas analises. O foco da disciplina seriam os processos de desenvolvimento econômico, e a questão ambiental seria vista como atraso, sendo que a área seria carente de teorias que se prestem a analisar a dimensão ambiental.

O autor então propõe algumas abordagens, como a "reflexão da hipótese", que diz que a sensibilidade ambiental é proporcionada pela cobertura dada pela mídia, e não pela percepção do problema. Sendo que em locais onde a degradação é mais obvia, não necessariamente encontraremos uma população mais sensível ao problema. (HANNINGAN, 1995).

A recomendação de Hanningan, no entanto, é a de que os sociólogos deveriam analisar as questões ambientais olhando para a maneira como o problema é colocado, para quem são os formuladores de exigências, qual a retorica e convencimento e para quem legitima o problema. Mas embora reconheça a papel da mídia, do Estado e dos movimentos sociais, Hanningan afirma que todo problema ambiental necessita de 
embasamento cientifico. No que toca a mudança climática, mostramos que o tema se legitima pela ciência, atingindo a visibilidade que tem em grande medida, por causa do IPCC. Não obstante, percepção publica do fenômeno não caminha par a par com os relatórios da instituição. E a mídia, muitas vezes adota o caminho oposto, argumentando que o aquecimento global não seria tão grave quanto diz o IPCC, ou mesmo que, não estaria ocorrendo.

A questão das mudanças climáticas esta colocada dentro de uma questão maior, a questão ambiental. E esta é uma questão politica e social, mas que, ao contrario de outras questões, não pode ser resolvida somente dentro destas arenas, não podendo prescindir de embasamento cientifico (HANNINGAN, 1995).

Papel fundamental exercem as comunidades epistêmicas, que no caso do aquecimento global, tanto podem ser formadas por cientistas do clima, por ambientalistas ou mesmo por setores relacionados ao petróleo. Mas também é possível que um Estado forte, ou ao menos estratégico, imponha uma pauta ambiental global, visando o equilíbrio politico interno, ou esteja sendo movido por algum grupo de interesse (que exerce pressão sobre esse Estado). (ANTONUCCI, 2010). Seria razoável supor, por exemplo, que no Brasil os usineiros da cana de açúcar possuam interesse em mecanismos de mitigação de carbono.

Hanningan não fala especificamente de mudanças climáticas, e desde a publicação de "Environmental Sociology", houve alguns avanços nas abordagens. No entanto, Hanningan já anuncia alguns conceitos que vieram a se tornar importantes nas abordagens sociológicas acerca de temas ambientais.

Em primeiro lugar o principio de precaução, característico da sociedade de risco. Em linhas gerais este principio diz respeito a cobrar da ciência que sempre se deve considerar o risco inerente a uma inovação. É claro, o conceito apresenta controvérsias, como a alegação de que isto se trata de politica, não de ciência. Giddens (2009) afirma que o principio da precaução nada tem de ciência, sendo oriundo de uma dada vertente do ambientalismo que valoriza uma natureza intacta. Esta postura, no entanto, em nada nos ajudaria a mitigar as consequências da degradação ambiental, que deveriam ser combatidas com mais inovações tecnológicas, segundo o autor.

Hanningan também aborda o conceito de comunidades epistêmicas. Estas seriam comunidades transnacionais de especialistas, científicos ou não, que tanto legitimam questões quanto influenciam tomadas de decisão (HANNINGAN, 1995). A comissão de estratigrafia, que discute sobre o Antropoceno, seria uma comunidade epistêmica. $\mathrm{O}$ IPCC seria composto por comunidades epistêmicas.

Não estamos afirmando que Hanningan criou o termo, tampouco que tenha sido o seu difusor. Mas o conceito está implícito na obra de outros autores que pensaram sociologicamente sobre as questões ambientais, como Beck e Latour (BECK, 2011; LATOUR 1994, 2004).

Estes dois autores, mas não somente eles pensam as questões ambientais em um quadro de questionamento da modernidade, comumente chamado de pós-modernidade (BECK, 2011; LATOUR 1994, 2004). 
Latour realiza uma critica mais radical, questionando a concepção cientifica sobre a natureza. E neste questionamento, faz a sua grande critica ao projeto moderno: a de que a modernidade consiste de uma ontologia que constrói uma separação radical entre sociedade e natureza (LATOUR, 1994).

Esta ontologia não passaria de um artificialismo para o autor, pois os fatos seriam de natureza hibrida. As crises ambientais, no entanto, teriam a propriedade de desnudar essa ideologia. As ciências seriam as grandes instancias responsáveis por manter a artificialidade de construção, pois insistiriam na separação das esferas na hora de construir o conhecimento. E para melhor compreender a ciência e a modernidade, deveríamos primeiramente olhar para as "caixas-pretas" e as redes (LATOUR, 1994; 2000).

Quando as pesquisas se concluem, quando uma nova descoberta ou formulação cientifica é realizada, os resultados aparecem como prontos e inquestionáveis. Ocorre, no entanto, que este processo nunca é puramente factual. Antes de um novo conhecimento cientifico se estabelecer, ele deve interagir com o conhecimento já estabelecido e disputar seu espaço. E nesta disputa, entram diversos outros fatores, que não somente o supostamente frio e imparcial processo de pesquisa (KUHN, 1998; LATOUR, 2000), como se pode perceber em torno da questão climática. Aqui estariam envolvidos cientistas, mídia, publico, policy makers, etc. e aqui também parece ser o caso da suposta pressão que sofreriam os cientistas do IPCC para serem amenos: previsões que aparentemente seriam realistas, em contraste com o conhecimento e a percepção estabelecidos sobre o tema, pareceriam "alarmistas", deslegitimando assim seus autores. E sendo deslegitimados, teriam dificuldades em publicar, e se não publicam, não podem realizar sua ciência.

Outra vertente fundamental de analise diz respeito à sociedade de risco, em especial, na obra de Ulrich Beck. O livro "Risk Society" fora escrito na década de 1980, quando o debate ambiental já começava a ganhar a sociedade como um todo, aliciando movimentos sociais. $\mathrm{O}$ desastre nuclear de Chernobyl fora um marco do período.

Neste trabalho Beck questiona alguns pilares da modernidade. O risco social, ambiental e político modificaria comportamentos clássicos, como a estrutura da família burguesa, participação social e legitimidade da ciência (BECK, 2011).

O conceito de risco repousa na incerteza. As projeções seriam sempre feitas para o futuro, e se baseariam em parâmetros incertos. A ciência, no entanto, ainda é a instancia legitima de construção de conhecimento, e mesmo na definição dos riscos. Mas já não pode mais operar a parte de outras esferas da sociedade, pois passa a ser constantemente questionada (BECK, 2011).

O questionamento também viria de dentro, pois a ciência da sociedade de risco teria uma tendência de se hiper-especializar, o que resulta em desconhecimento e deslegitimação mutua entre os especialistas, resultando em mais incertezas. E diante do aumento destas incertezas, a ciência responderia com mais especializações (BECK, 2011). O próprio desenvolvimento da ciência que se hiper-especializar, contribui para o surgimento de controvérsias em torno do clima. E embora os parâmetros do IPCC não 
sejam tão incertos quanto argumentam os céticos, ainda assim são parâmetros que se baseiam em previsões de cenários que sempre se alteram.

Giddens escreve especificamente sobre as mudanças climáticas, colocando-a em um quadro de crise ambiental e de modernidade. Ele aborda diversas dimensões da questão, desde a ação individual (poupar combustível, utilizar produtos sustentáveis, etc.) até as consequências geopolíticas das mudanças climáticas, passando por controvérsias de ciência e critica ao capitalismo (GIDDENS, 2009).

Giddens admite a existência dos riscos, chegando a comparar os riscos do aquecimento global a extinção de diversas sociedades do passado que consumiram seus recursos naturais e entraram em colapso, como os nativos da Ilha de Pascoa (GIDDENS, 2009; JARED, 2005). No entanto, afirma que riscos são uma oportunidade de reestruturação politica e tecnológica.

Giddens (2009) credita ao ambientalismo a promoção do tema, mas atualmente o objeto vem sendo reivindicado por varias outras correntes, da ciência e da politica. $\mathrm{O}$ risco então desafiaria as posições politicas de esquerda e de direita, pois transcenderia as ideologias. Mas o caminho inverso também ocorreria: dada a grande aceitação do tema, outras ideologias o utilizariam, como os defensores da União Europeia (a justificativa é a de que seria mais fácil a implementação de politicas de mitigação).

Giddens também fala sobre a modernidade reflexiva (1991). Sem se posicionar se estaríamos vivendo já uma pós-modernidade, Giddens admite que a modernidade já atingiu características distintas do que previam os clássicos da sociologia. Existiria então uma infinidade de identidades e conhecimentos com os quais o individuo pode se identificar. Mas ao contrario da tradição, se trataria de uma escolha, a qual não possui nenhuma garantia de se manter ou de ser aceita pelos demais. Talvez por isso faça sentido em pensar a questão climática como mais controversa do que realmente é.

A ciência perde importância, mas ainda é uma forma legitima de conhecimento. E o acesso ao conhecimento, não se faz de maneira homogenia (GIDDENS, 1991). Sendo assim, os céticos se valem das incertezas em torno do conhecimento que se tem sobre o clima para deslegitimar o IPCC. O IPCC, por outro lado, não é totalmente simétrico. A maior parte da pesquisa feita sobre o clima se concentra nos EUA, Suíça, Alemanha e Japão (SCHOIJET, 2008), diminuindo a confiabilidade que se tem em relação aos dados de países como o Brasil. Somente ter conhecimento, no entanto, não significa agir, como é o caso dos EUA, que investe pesadamente em pesquisa sobre o clima, mas que, até o presente momento, tem se mostrado refratário a qualquer acordo de redução de gases do efeito estufa (BBC BRASIL, 2007; SCHOIJET, 2008).

Embora os science studies já tenham mostrado há um bom tempo, que a ciência na pratica não opera conforme as clássicas normas mertonianas, os argumentos dos céticos negacionistas não se mostram razoáveis, e suas criticas ao IPCC não contribuem significativamente para o debate em torno da questão climática. 
Mesmo assim, dado o interesse global do tema, há que se compreender melhor como o IPCC funciona: como seus relatórios interagem com outras instancias da sociedade, e como se dá sua dinâmica interna.

Existem diversos estudos sobre a relação do IPCC com o exterior, mas pouquíssimos em torno de sua dinâmica interna. Em 2013, uma equipe estado-unidense de sociólogos da ciência anunciou a intenção de realizar um estudo dessa natureza, correlacionando a dinâmica do órgão e maneira como isso afeta os resultados. Pretendem "abrir a caixa preta" do IPCC, para usar uma expressão consagrada por Latour e os Science Studies (Nature, 2013).

Esta pesquisa já havia sido tentada em 2010, mas o acesso foi negado pelo órgão. Está presente na equipe, a historiadora da ciência Naomi Oreskes (Nature, 2013), (referencia no presente trabalho) autora de "Merchants of Doubt", livro que procura mostrar um suposto mau uso da ciência, onde indivíduos com grande capital politico se valem das suas credencias de cientistas para criarem falsas controvérsias em torno dos males do tabaco e da realidade do aquecimento global.

\section{Considerações finais}

Argumentamos aqui que aquecimento global é um tema interdisciplinar por natureza. Diversas teorias sociais se prestam a compreensão do fenômeno (não do fenômeno climático em si, mas de todos os fatores envolvidos, a rede do clima, como mencionado).

Trata-se de um tema de sociologia da ciência, mas há que se ter cuidado para que não se perca em falsas controvérsias, como as suscitadas pelos céticos. O problema legítimo aqui é a participação das ciências sociais no debate, a qual ainda é pequena, mas deveria ser maior. Primeiramente porque, como já dito, o tema é interdisciplinar por natureza, e não se resolve somente nos laboratórios. Combater e mitigar as mudanças climáticas implica em reestruturação politica e mudanças de comportamento, o que estaria dentro da competência das ciências sociais.

Não foi nosso objetivo aqui mostrar qual teria social seria a mais apropriada para uma melhor compreensão dos diversos fatores que envolvem a discussão sobre mudança climática, mas mostrar a necessidade de mais participação destas áreas em torno do tema. Ilustramos então como importantes conceitos de Latour, Hanningan, Beck e Giddens enriquecem a discussão. E para dar continuidade a discussão, sugerimos que pesquisas futuras deveriam se dedicar a investigar o porque dessa baixa participação.

\section{Referencias}

ABRAMOVAY, R. 2014. Inovações para que se Democratize o acesso a Energia sem ampliar as Emissões. In: Ambiente e Sociedade, v. 17, n. 3. pp. 1-18

AGENCIA FAPESP. Onça-Pintada pode desaparecer da Mata Atlântica. 09 de janeiro de 2014. Disponível em: <http://agencia.fapesp.br/oncapintada_pode_desaparecer_da_ mata_atlantica/18445/. Acesso em fevereiro de 2014 
ANTONUCCI, L. Le Politiche Pubbliche Ambientali. In: MIGLIAVACCA, M.; RIGAMONTI, L. (Org.) Cambiamenti Climatici: um approccio interdisciplinare per capire um pianeta in trasnformazione. Bolonha: società editrice il mulino. 2010.

BBC BRASIL. Entenda o que é o IPCC e suas conclusões. 14 de novembro de 2007. Disponível em: <http://www.bbc.co.uk/portuguese/reporterbbc/story/2007/11/071107_ ipcc_qa_pu.shtml >. Acesso em fevereiro de 2015.

BECK, U. Sociedade de Risco: rumo a uma nova modernidade. São Paulo: Editora 34. Publications. 2011.

BRYSSE, K.; ORESKES, N.; O'REILLY, J.; OPPENHEIMER, M.;. 2013. Climate Change Prediction: erring on the side of the least drama?. In: Global Environmental Change. v. 23, pp. 327-337

DOEL, R. E. 2003. Constituting the Postwar Earth Sciences: The Military's Influence on the Environmental Sciences in the USA after 1945. In: Social Studies of Science, V. 33, 5: pp. 635-666.

FERNANDEZ, V.; ALVES, E.; MARQUES, I.; PREMEBIDA, A.; ESTEVES, B. 2014. "Praticando Nautimodelismo as Avessas." In: ARAUJO, J. F. M.; VALENTE, C. M. (Org.) Ator Rede e além... no Brasil: as teorias que aqui gorjeiam não gorjeiam como lá? Campina Grande: eduepb.

FERREIRA, L. C. 2001. Sociologia Ambiental, teoria social e a produção intelectual no Brasil Idéias, Campinas, v. 10, p. 39-70, 2001.

GIDDENS, A. As Consequências da Modernidade. São Paulo: ed. Unicamp. 1991.

GIDDENS, A. A Politica da Mudança Climática. Zahar: Rio de Janeiro. 2009

HANNINGAN, J. A. Sociologia Ambiental: a formação de uma perspectiva ambiental. Lisboa: Instituto Piaget. 2009.

HUNG, M.; TSAI, T. 2012. Dilemma of Choice: China's response to climate change. In: Revista Brasileira de Politica Internacional. 55 (specia edition) pp. 104-124

IPAM. ABC do Clima. 04 de fevereiro de 2015. Disponível em: < http://www.ipam.org. $\mathrm{br} /$ saiba-mais/abc/mudancaspergunta/O-que-e-o-Protocolo-de-Quioto-/20/10>. Acesso em fevereiro de 2015.

JARED, M. D. Collapse: how societies choose to fail or succeed. Nova York: Viking press. 2005

KUHN, T. A Estrutura das Revoluções Cientificas. 5. ed. São Paulo: Editora Perspectiva. 1998

LATOUR, B. Ciência em ação: como seguir cientistas e engenheiros sociedade afora. São Paulo: Editora Unesp, 2000.

LATOUR, B. Jamais fomos Modernos - ensaios de antropologia simétrica. São Paulo: Editora 34, 1994. 
LATOUR, B. Políticas da Natureza: como fazer Ciência na democracia. Bauru: Edusc, 2004

LATOUR, B. Reagregando o Social-uma introdução a teoria ator rede. Salvador/Bauru: EDUFBA/EDUSC, 2012.

LATOUR, B. Reflexão sobre o Culto Moderno dos Deuses Fe(i)tiches. Bauru: Edusc. 2012a

LEITE, J.C. 2014 Controvérsias cientificas ou negação da ciência? A agnotologia e a ciência do clima. Sci. stud. [online]. 2014, vol. 12, nº 1, pp. 179-189.

LEIS, H. R. A Modernidade Insustentável- às criticas do ambientalismo a sociedade contemporânea. Montevidéo: Coscoroba, 2004

MARTINS, R. D.; FERREIRA, LEILA. C. Assessing the Research on Human Dimensions of Global Environmental Change in Latin America. Teoria \& Pesquisa, v. XVII, p. 31-52, 2009.

Nature, 2013. Study aims to put IPCC under a Lens - social scientists wants to examine how climate panel's internal dynamics affect outcomes. V 502, pp. 281

NISBET, M. C.; MYERS, T. The Polls- Trends. twenty years of public opinion about global warming. Oxford: Public Opinion Quarterly, v. 71, No. 3, 2007, pp. 444-4

NOZAWA. M. L. R. As Mudanças Climáticas como Problema Politico: revisão de literatura. São Carlos, 2010.

ORESKES, N. The Scientific Consensus on Climate Change: how do we now we're not wrong? In: DiMENTO, J. F. C.; DOUGHMAN, P. (Ed.) Climate Change: What It Means for Us, Our Children, and Our Grandchildren. Massachusetts: MIT press. 2007

ORESKES, N. ;CONWAY, E. M. Merchants of Doubt: how a handful of scientists obscured the truth on issues from tobacco smoke to global warming. New York, Berlim, London: Bloomsbury. 2010

OROMBelli, G. Premessa. In: MigliaVACCA, M.; RIGAMONTI, L. (Org.) Cambiamenti Climatici: um approccio interdisciplinare per capire um pianeta in trasnformazione. Bolonha: società editrice il mulino. 2010.

PESQUISA FAPESP. Luciana Vanni Gatti: na trilha do carbono. Edição 217, março de 2014. Disponível em: <revistapesquisafapesp.br>. Acesso em agosto de 2014

PROTOCOLO DE KYOTO INFO. Conferencias sobre o meio ambiente. 04 de fevereiro de 2015. Disponível em: <http://protocolo-de-kyoto.info/mos/view/ Confer\%C3\%AAncias_sobre_Meio_Ambiente/> Acesso em fevereiro de 2015

RIVA, P. La Percezione Sociale del Cambiamento Climatico. In: MIGLIAVACCA, M.; RIGAMONTI, L. (Org.) Cambiamenti Climatici: um approccio interdisciplinare per capire um pianeta in trasnformazione. Bolonha: società editrice il mulino. 2010.

RIVA, P.; ANTONUCCI, L.; MELONI, R.; PANAIT, A. M.; MARTANI, C.; MIGLIAVACC, M.; RIGAMONTI, L. Strategie e Azioni Future per la Mitigazione 
e l'Adattamento. In: MIGLIAVACCA, M.; RIGAMONTI, L. (Org.) Cambiamenti Climatici: um approccio interdisciplinare per capire um pianeta in trasnformazione. Bolonha: società editrice il mulino. 2010.

SCHOIJET, M. Límites del Crecimiento y Cambio Climático. Mexico, D. F.: siglo XXI. 2008

UNITED NATIONS (UN). Local Governments' International Mid Term Evaluation Conference on the Millennium Development Goals (MDGs). Roma: 2007

VIOLA, E. O Regime Internacional da Mudança Climática e o Brasil. Revista Brasileira de Ciências Sociais, v. 17, n. 50, p. 25-46. 2002.

Allan Rogério Veltrone

Doutorando em Ciência, Tecnologia e Sociedade pela UFSCar. Mestre em Ciência, Tecnologia e Sociedade pela UFSCar. Graduado em Ciências Sociais com ênfase em antropologia pela UFSCar. Tem atuado nas áreas de antropologia e sociologia do meio ambiente e antropologia e sociologia da ciência. bolsista CNPQ/CAPES.

Rua Madre Tereza de Calcutá, 436, Jardim Acapulco. CEP 13563-708. São

Carlos-SP.

E-mail: allanveltrone@gmail.com

Recebido para publicação em agosto de 2015 Aprovado para publicação em outubro de 2016 